\title{
PENGARUH PEMBELAJARAN EKONOMI, LINGKUNGAN SOSIAL BUDAYA, DAN SIKAP BERKONSUMSI TERHADAP PERILAKU KONSUMSI YANG BERKARAKTER
}

\author{
Diah Syifaul A'yuni \\ Institut Pesantren KH. Abdul Chalim Mojokerto \\ Email: diah.ayuni87@gmail.com
}

\begin{abstract}
Character building applied in the world of education, especially those related to economic education that aims to produce professional educators in the field of education as well as scientists in the field of education and economics. This study discusses the issue of character buiding in consumption behavior which is very important because it is the goal of national education. The consumption behavior characterized is influenced by several variables, among others: economic learning received in schools, social-cultural environment where a person lives and attitude to consume that upholds the values contained in Pancasila. Findings show that all variables directly affect consumption behavior characterized.
\end{abstract}

Keywords: consumption behavior, social-cultural environment, economic learning

\begin{abstract}
ABSTRAK
Pembentukan karakter sangatlah diperlukan diterapkan di dunia pendidikan terutama yang berkaitan dengan pendidikan ekonomi yang bertujuan untuk menghasilkan tenaga pendidik profesional serta ilmuwan di bidang pendidikan dan ilmu ekonomi. Penelitian ini membahas masalah pembentukan karakter dalam perilaku konsumsi seseorang yang sangat penting karena merupakan tujuan dari pendidikan nasional. Beberapa variabel yang sangat berpengaruh adalah pembelajaran ekonomi yang mereka peroleh di kampus, lingkungan sosial budaya tempat mereka tinggal dan sikap berkonsumsi. Hasil dari penelitian ini menunjukkan bahwa variabel-variabel yang tersebut mempengaruhi perilaku konsumsi yang berkarakter sesuai dengan nilai-nilai luhur Budaya Bangsa yang menjunjung tinggi nilai-nilai yang terkandung dalam pancasila.
\end{abstract}

Kata kunci: perilaku konsumsi, pembelajaran ekonomi, lingkungan sosial budaya.

\section{PENDAHULUAN}

Kepedulian terhadap masalah karakter dan moral yang ada di Indonesia akhirakhir ini sangat kurang, salah satu wujud paling nyata dari hancurnya karakter bangsa adalah merebaknya korupsi, kolusi dan nepotisme di semua bidang kehidupan. Karakter Bangsa Indonesia adalah karakter yang berlandaskan Pancasila yang memuat elemen kepribadian yang sama-sama diharapkan sebagai jati diri bangsa. Akan tetapi, yang terjadi belakangan ini justru bertolak belakang dengan kepribadian manusia, sifat ramah tamah, sopan santun dan suka menolong yang sering dilekatkan kepada Bangsa Indonesia ternyata telah mengalami penurunan atau perusakan. 
Pembentukan karakter sangatlah diperlukan diterapkan di dunia pendidikan terutama yang berkaitan dengan pendidikan ekonomi yang bertujuan untuk menghasilkan tenaga pendidik profesional serta ilmuwan di bidang pendidikan dan ilmu ekonomi, mereka akan ikut andil dalam membentuk manusia sebagai calon pengusaha yang profesional dan peduli dengan lingkungan perekonomian serta mempersiapkan peserta didik untuk memiliki pengetahuan, keterampilan dan sikap yang diperlukan oleh pelaku-pelaku ekonomi di masa mendatang dengan berbagai permasalahan ekonomi yang semakin kompleks baik di tingkat nasional maupun global.

Keadaan ini juga terjadi pada perilaku konsumsi yang dilakukan oleh mahasiswa memperlihatkan keadaan yang kurang mendapat perhatian dari dunia pendidikan termasuk dalam pembentukan karakter dalam perilaku konsumsi seseorang. Pembentukan karakter merupakan salah satu tujuan pendidikan nasional. Pasal I UU Sisdiknas tahun 2003 menyatakan bahwa di antara tujuan pendidikan nasional adalah mengembangkan potensi peserta didik untuk memiliki kecerdasan, kepribadian dan akhlak mulia

\section{PERILAKU KONSUMSI YANG BERKARAKTER}

Schiffman dan Kanuk (2004:7) mengemukakan "The term consumer behavior refers to the behavior that consumers display in searching for, purchasing, using, evaluating, and disposing of products and services that they expect will satisfy their needs". Istilah perilaku konsumen diartikan sebagai perilaku yang diperlihatkan konsumen dalam mencari, membeli, menggunakan, mengevaluasi dan menghabiskan barang dan jasa yang mereka harapkan akan memuaskan kebutuhan mereka. Sedangkan Engel, Blackwell dan Miniard (1994:4) mendefinisikan perilaku konsumen sebagai suatu tindakan yang langsung terlibat dalam mendapatkan, mengkonsumsi, dan menghabiskan produk dan jasa, termasuk proses keputusan yang mendahului dan mengikuti tindakan ini."

Deliarnov (1997:131-133) menjelaskan pola perilaku orang terikat dengan masyarakat sekeliling, dan orang dalam tingkah lakunya berusaha ikut menunjang terhadap perkembangan masyarakat. Menurut Soedarsono (2005) karakter adalah tata 
nilai yang mewujud dalam sistem daya dorong atau driving system yang melandasi pemikiran, sikap, dan perilaku.

Menurut Kohlberg (dalam Disman, 2004:121) menyatakan bahwa nilai-nlai perilaku ekonomi seperti konsumsi yang kita tumbuh kembangkan adalah perilaku yang sesuai dengan nilai-nilai moral yang dianut dalam masyarakat. Perilaku konsumsi yang dimaksud adalah tidak lepas dari budaya Bangsa yang diantaranya memiliki dimensidimensi yaitu seperti yang diungkapkan oleh Harris and Moran (Dalam Jhundra-indra, 2009:60) "the dimension of national culture, on the other hand, is empirically based; culture is the sense of self and space, communication and languages, time conscious, value and norms, beliefs and attitudes, and work habits and practices. Dari pernyataan tersebut, dapat disimpulkan perilaku konsumsi yang berkarakter dalam budaya bangsa Indonesia menganut ideologi bangsa yaitu Pancasila. (Agil dan Omar, 2007:78).

\section{PEMBELAJARAN EKONOMI}

Ekonomi merupakan ilmu tentang perilaku dan tindakan manusia untuk memenuhi kebutuhan hidupnya yang bervariasi, dan berkembang dengan sumber daya yang ada melalui pilihan-pilihan kegiatan produksi, konsumsi dan/atau distribusi (Faruq, 2011:56). Ekonomi juga merupakan ilmu sosial yang pembelajarannya bertujuan untuk mengembangkan karakter warga negaranya sebagai mana dikemukakan Barr (Dalam Disman, 2004:55) bahwa “... conform to certain accepted practice, hold particular beliefs, is loyal to certain value, participates in certain activities, and conforms to norms which are often in character".

Menurut Hamalik (2010:57) pembelajaran adalah suatu kombinasi yang tersusun meliputi unsur-unsur manusiawi, material, fasilitas, perlengkapan, dan prosedur yang saling mempengaruhi mencapai tujuan pembelajaran. Pembelajaran ekonomi merupakan dasar pembelajaran karakter bagi peserta didik dalam meletakkan dasardasar berperilaku ekonomi yang benar. Fungsi utama dari pendidikan ekonomi ialah enkulturasi, pembudayaan atau internalisasi tata nilai dan adat istiadat masyarakat dengan tujuan supaya nilai-nilai lama yang dianggap luhur sekaligus menjamin kepribadian khas masyarakat tidak luntur dan tetap terjaga kelanggenannya. 
Dari pengertian di atas, dapat disimpulkan bahwa pembelajaran ekonomi adalah kombinasi antara komponen-komponen sebuah proses yang mengajarkan tentang perilaku dan tindakan manusia dalam memenuhi kebutuhan hidup.

\section{LINGKUNGAN SOSIAL BUDAYA}

Sistem nilai budaya yang berkembang dalam masyarakat telah menjadi pedoman ideal dalam menyikapi obyek tertentu, tidak terkecuali terhadap pembangunan ekonomi, pembangunan politik, sebagaimana Koentjaraningrat (1991:13) mengatakan bahwa nilai budaya menentukan sikap seseorang terhadap objek tertentu. Dimana sistem nilai budaya terdiri dari konsep-konsep yang hidup dalam pikiran mayoritas warga masyarakat. Berarti sistem nilai budaya dalam masyarakat merupakan ciri khas serta menjadi aturan sakral bagi perilaku setiap orang dalam masyarakat yang menyebabkan nilai budaya tersebut melekat serta sangat sukar mengalami perubahan

Dalam perilaku konsumsi budaya diartikan sebagai keseluruhan keyakinan belajar, nilai, dan kebiasaan yang berfungsi untuk mengarahkan perilaku konsumen dari anggota masyarakat tertentu (schiffman \& Kanuk, 2004:408). Faktor budaya merupakan suatu yang paling memiliki pengaruh paling luas pada perilaku konsumen. Sajogyo (1982:34) menguraikan pandangan umumnya tentang nilai budaya bahwa faktor-faktor mental itu adalah pengetahuan mengenai sistem nilai budaya (cultural value system) dan mengenai sikap (attitudes).

\section{SIKAP BERKONSUMSI}

Sikap adalah kesediaan mental individu untuk menanggapi suatu obyek di lingkungan sosialnya, baik bersifat netral, maupun negatif melalui komponen kognisi, afeksi dan konasi yang berfungsi sebagai pembimbing dan pengarah tindakan/perilaku individu (Disman, 2004:106). Schiffman \& Kanuk (2004:253) mengungkapkan "an attitude is a learned predisposition to behave in a consistently favorable or unfavorable way with respect to a given object". Sikap merupakan suatu kecenderungan untuk mengadakan reaksi secara tertentu terhadap sesuatu secara sadar atau tidak sadar, rasional atau tidak rasional. 
Bany dan Johnson (1975:377-378) menjelaskan konsep sikap sebagai berikut: 1). Attitude are social learning artinya sikap it u merupakan hasil belajar dalam hubungan sosial dengan orang lain 2). Attitude have readiness to respond artinya sikap merupakan kesiapan atau kecenderungan bertindak dalam kaitannya dengan suatu obyek, dan 3). Attitude are inferred artinya sikap itu merupakan suatu penafsiran bagi perilaku seseorang yang mungkin menjadi indikator yang sempurna atau mungkin pula tidak sempurna.

\section{METODE PENELITIAN}

Penelitian ini merupakan penelitian eksplanatori (explanatory research) dengan pendekatan kuantitatif dengan tujuan untuk menganalisis dan menjelaskan hubungan kausalitas variabel-variabel penelitian melalui pengujian hipotesis. Penelitian ini menguji pengaruh pembelajaran ekonomi (X1), lingkungan sosial budaya (X2), dan sikap berkonsumsi (X3) terhadap perilaku konsumsi yang berkarakter (Y) pada mahasiswa Pendidikan Ekonomi Fakultas Ekonomi Universitas Negeri Malang baik langsung maupun tidak langsung.

Populasi dalam penelitian ini adalah seluruh mahasiswa Pendidikan Ekonomi Fakultas Ekonomi Universitas Negeri Malang yang menempuh mata kuliah ekonomi koperasi yang berjumlah 233 mahasiswa.

\section{DATA, INSTRUMEN DAN TEKNIK PENGUMPULAN DATA}

Data penelitian ini merupakan data primer, yaitu data yang secara langsung diperoleh dari responden melalui penyebaran kuesioner. Instrumen penelitian yang digunakan untuk memperoleh data dan mengukur variabel yang diteliti yaitu dengan mengunakan kuosioner yang berisi pernyataan-pernyataan yang harus dijawab oleh responden yaitu mahasiswa Fakultas Ekonomi progam studi pendidikan ekonomi pembangunan yang menempuh mata kuliah ekonomi koperasi yang merupakan sampel dari penelitian ini.

Kuesioner atau angket untuk mengukur variable-variabel dalam penelitian ini terdiri atas sejumlah pernyataan objektif dengan 5 alternatif jawaban dan diukur dengan skala likert dengan sistem penilaian jenis instrumen ini adalah skor 5,4,3,2,1. 
Suatu instrumen dikatakan baik, jika instrumen itu valid dan reliabel. Dari pengujian validitas diperoleh hasil bahwa Corrected Item-Total Correlation (r hitung) lebih besar dari $\mathrm{r}$ tabel. Hasil pengujian reliabilitas instrument diperoleh bahwa Cronbach Alpha dari masing-masing variabel lebih besar dari 0,60 sehingga dapat disimpulkan bahwa item dari masing-masing variabel reliabel.

\section{TEKNIK ANALISIS DATA}

Sesuai dengan rumusan masalah dan tujuan penelitian, serta hipotesis yang diuji dalam penelitian ini, maka teknik analisis data yang dipergunakan dalam penelitian ini adalah analisis multivariat yaitu analisis jalur (path analysis) untuk mempelajari efek langsung (direct effect) maupun efek tidak langsung (indirect effect) dari variabel eksogen terhadap variabel endogen Langkah-langkah analisis jalur ini adalah: mengajukan model konseptual, membuat spesifikasi model analisis, menguji asumsi yang melandasi, mengoperasikan model analisis jalur dengan komputer

\section{HASIL DAN PEMBAHASAN}

Paparan data masing-masing variabel diperoleh dalam tabel 1,2,3, dan 4 . Pertama, hasil pengujian data variabel perilaku konsumsi dapat dilihat dalam tabel 1 berikut:

Tabel 1 Distribusi Frekuensi Perilaku Konsumsi yang Berkarakter Mahasiswa S1 Pendidikan FE-UM

\begin{tabular}{|c|l|l|c|c|}
\hline \multirow{2}{*}{ No } & \multirow{2}{*}{ Skor interval } & \multirow{2}{*}{ Kriteria } & \multicolumn{2}{c|}{ Frekuensi } \\
\cline { 4 - 5 } & & & F & \% \\
\hline 1. & $51-57$ & sangat tidak berkarakter & 10 & $6,80 \%$ \\
\hline 2. & $58-64$ & tidak berkarakter & 16 & $10,88 \%$ \\
\hline 3. & $65-71$ & cukup berkarakter & 66 & $44,90 \%$ \\
\hline 4. & $72-78$ & berkarakter & 39 & $26,53 \%$ \\
\hline 5. & $79-85$ & sangat berkarakter & 16 & $10,88 \%$ \\
\hline \multicolumn{3}{|c}{ JUMLAH } & 147 & $100 \%$ \\
\hline
\end{tabular}

(Sumber: diolah peneliti, 2012)

Kedua, Hasil pengujian data varibel pembelajaran ekonomi dapat dilihat dalam tabel 2 berikut: 
Tabel 2 Distribusi Frekuensi Pembelajaran Ekonomi Mahasiswa S1 Pendidikan FEUM

\begin{tabular}{|c|l|l|c|c|}
\hline \multirow{2}{*}{ No } & \multirow{2}{*}{ Skor interval } & \multirow{2}{*}{ Kriteria } & \multicolumn{2}{c|}{ Frekuensi } \\
\cline { 4 - 5 } & & & F & \% \\
\hline 1. & $29-33$ & sangat tidak baik & 8 & $5,44 \%$ \\
\hline 2. & $34-38$ & tidak baik & 44 & $29,93 \%$ \\
\hline 3. & $39-43$ & cukup baik & 63 & $42,86 \%$ \\
\hline 4. & $44-48$ & baik & 20 & $13,61 \%$ \\
\hline 5. & $48-52$ & sangat baik & 12 & $8,16 \%$ \\
\hline \multicolumn{2}{|c|}{ JUMLAH } & 147 & $100 \%$ \\
\hline
\end{tabular}

(Sumber:diolah peneliti,2012)

Ketiga, hasil pengujian data variable lingkungan sosial budaya yang dapat dilihat dalam tabel 3 berikut:

Tabel 3 Distribusi Frekuensi Lingkungan Sosial Budaya Mahasiswa S1 Pendidikan FEUM

\begin{tabular}{|c|l|l|c|c|}
\hline \multirow{2}{*}{ No } & \multirow{2}{*}{ Skor interval } & \multicolumn{1}{|c|}{ Kriteria } & \multicolumn{2}{c|}{ Frekuensi } \\
\cline { 4 - 5 } & & & F & \% \\
\hline 1. & $27-30$ & sangat tidak baik & 7 & 4,76 \\
\hline 2. & $31-33$ & tidak baik & 28 & 19,05 \\
\hline 3. & $34-36$ & cukup baik & 39 & 26,53 \\
\hline 4. & $37-39$ & baik & 47 & 31,97 \\
\hline 5. & $40-43$ & sangat baik & 26 & 17,69 \\
\hline \multicolumn{2}{|r}{ JUMLAH } & 147 & $100 \%$ \\
\hline
\end{tabular}

(Sumber: diolah peneliti, 2012)

Keempat, Hasil pengujian data variabel sikap berkonsumsi dapat dilihat dalam tabel 4 berikut:

Tabel 4 Distribusi Frekuensi Sikap Berkonsumsi Mahasiswa S1 Pendidikan FE-UM

\begin{tabular}{|c|l|l|c|c|}
\hline \multirow{2}{*}{ No } & \multirow{2}{*}{ Skor interval } & \multirow{2}{*}{ Kriteria } & \multicolumn{2}{|c|}{ Frekuensi } \\
\cline { 3 - 5 } & & & F & $\%$ \\
\hline 1. & $30-32$ & sangat tidak baik & 24 & $16,33 \%$ \\
\hline 2. & $33-35$ & tidak baik & 36 & $24.49 \%$ \\
\hline 3. & $36-38$ & cukup baik & 50 & $34,01 \%$ \\
\hline 4. & $39-41$ & baik & 18 & $12,24 \%$ \\
\hline
\end{tabular}




\begin{tabular}{|l|l|l|c|c|}
\hline 5. & $42-45$ & sangat baik & 9 & $6,12 \%$ \\
\hline \multicolumn{3}{|c|}{ JUMLAH } & 147 & $100 \%$ \\
\hline
\end{tabular}

(Sumber: diolah peneliti, 2012)

Sedangkan hasil uji normalitas menunjukkan bahwa nilai Kolmogrof-Smirnov berkisar diantara 1,101 hingga 1,356 dan seluruhnya signifikan diatas 0,05. Dengan demikian dapat disimpulkan bahwa sebaran data untuk seluruh variabel dapat dinyatakan berdistribusi normal. Dan dari grafik atau scatterplot menunjukkan bahwa plot-plot tersebar secara acak dan tidak membentuk suatu pola tertentu baik diatas maupun dibawah angka 0 sumbu Y. Dengan demikian dapat ditarik kesimpulan bahwa tidak terjadi heteroskedastisitas. Serta Berdasarkan hasil pengujian diperoleh nilai toleransi dari masing-masing variabel lebih besar dari 0,10 dan nilai VIF (Varians Inflation Factor) dari semua variabel nilainya kurang dari 10. Dengan demikian dapat disimpulkan bahwa tidak ada multikolinearitas antar variabel independen dalam model ini.

Hasil uji data yang dilakukan menggunakan analisis jalur (path analysis) blok I menunjukkan bahwa nilai koefisien regresi blok I untuk pembelajaran ekonomi (X1) sebesar 0,265 dan nilai koefisien regresi variabel lingkungan sosial budaya (X2) sebesar 0,432. Hasil uji pengaruh variabel pembelajaran ekonomi (X1) terhadap sikap berkonsumsi (X3) diperoleh nilai t hitung sebesar 3,630 dan signifikansi 0,000. Sedangkan hasil uji untuk pengaruh variabel lingkungan sosial budaya (X2) terhadap sikap berkonsumsi (X3) diperoleh nilai t hitung sebesar 5,908 dan signifikansi t sebesar 0.000. Sedangkan nilai koefisien regresi blok II untuk pembelajaran ekonomi (X1) sebesar 0,367, lingkungan sosial budaya (X2) sebesar 0,230 dan sikap berkonsumsi (X3) sebesar 0,224. Hasil uji pengaruh variabel pembelajaran ekonomi (X1) terhadap perilaku konsumsi yang berkarakter (Y) diperoleh nilai t hitung sebesar 5,132 dan signifikansi 0,000. Sedangkan hasil uji untuk pengaruh variabel lingkungan sosial budaya (X2) terhadap perilaku konsumsi yang berkarakter (Y) diperoleh nilai t hitung sebesar 3,016 dan signifikansi t sebesar 0.003

Hasil analisis jalur yang dilakukan dalam penelitian ini merupakan kombinasi antara dua regresi linier. Berdasarkan hasil analisis regresi linier berganda sebelumnya 
dapat diketahui pengaruh langsung dari variabel X1 ke X3, X2 ke X3, X1 ke Y, X2 ke $\mathrm{Y}, \mathrm{X} 3 \mathrm{ke} \mathrm{Y}$, pengaruh tidak langsung dan pengaruh totalnya yang dapat dilihat pada table 5 berikut :

Tabel 5 Pengaruh langsung dan tidak langsung antara variabel X1, X2,X3 terhadap $Y$

\begin{tabular}{|l|c|c|c|c|}
\hline \multirow{2}{*}{ Variabel } & Koefisien & \multicolumn{3}{|c|}{ Pengaruh } \\
\cline { 3 - 5 } & jalur & Langsung & Tidak langsung & Total \\
\hline X1 terhadap X3 & 0,178 & 0,178 & & 0,178 \\
X2 terhadap X3 & 0,462 & 0,462 & & 0,462 \\
X1 terhadap Y & 0,457 & 0,457 & 0.043 & 0,500 \\
X2 terhadap Y & 0,221 & 0,221 & 0,111 & 0,332 \\
X3 terhadap Y & 0,241 & 0,241 & & 0,241 \\
$\varepsilon_{1}$ & 0,832 & 0,832 & & 0,832 \\
$\varepsilon_{2}$ & 0,689 & 0,689 & & 0,689 \\
\hline
\end{tabular}

(Sumber: diolah peneliti,2012)

Berdasarkan pada tabel diatas diketahui bahwa pengaruh langsung variabel pembelajaran ekonomi (X1) terhadap Sikap berkonsumsi (X3) sebesar 0,178. Pengaruh langsung variabel lingkungan sosial budaya (X2) terhadap sikap berkonsumsi (X3) adalah sebesar 0,462. Pengaruh langsung antara pembelajaran ekonomi (X1) terhadap perilaku konsumsi yang berkarakter (Y) sebesar 0,457. Pengaruh langsung antara lingkungan sosial budaya (X2) terhadap perilaku konsumsi yang berkarakter adalah sebesar 0,221. Dan pengaruh langsung sikap berkonsumsi (X3) terhadap perilaku konsumsi yang berkarakter adalah sebesar 0,241.

Berdasarkan pada hasil perhitungan diatas, dapat diketahui juga bahwa besarnya pengaruh tidak langsung antara variabel pembelajaran ekonomi $\left(\mathrm{X}_{1}\right)$ terhadap perilaku konsumsi yang berkarakter $(\mathrm{Y})$ melalui sikap berkonsumsi $\left(\mathrm{X}_{3}\right)$ adalah sebesar 0,043 sehingga, lingkungan sosial budaya $\left(\mathrm{X}_{2}\right)$ terhadap perilaku konsumsi yang berkarakter $(\mathrm{Y})$ melalui sikap berkonsumsi $\left(\mathrm{X}_{3}\right)$ adalah sebesar 0,111 . Serta besarnya pengaruh total variabel pembelajaran ekonomi $\left(\mathrm{X}_{1}\right)$ terhadap perilaku konsumsi yang berkarakter $(\mathrm{Y})$ melalui sikap berkonsumsi $\left(\mathrm{X}_{3}\right)$ adalah sebesar 0,500, pengaruh total variabel lingkungan sosial budaya $\left(\mathrm{X}_{2}\right)$ terhadap perilaku konsumsi yang berkarakter $(\mathrm{Y})$ melalui sikap berkonsumsi $\left(\mathrm{X}_{3}\right)$ adalah sebesar 0,332 .

Hasil pengolahan dan pengujian data menunjukkan Tingkat pembelajaran ekonomi yang baik yang diterima oleh mahasiswa dapat mempengaruhi sikap berkonsumsi yang baik yang sesuai dengan nilai dan norma Bangsa yaitu pancasila dan 
mempengaruhi perilaku konsumsi yang berkarakter. Tingkat pembelajaran ekonomi yang baik yang diterima oleh mahasiswa dapat mempengaruhi perilaku konsumsi yang berkarakter sesuai dengan nilai dan norma Bangsa yaitu pancasila. Sikap berkonsumsi yang baik dapat mempengaruhi perilaku konsumsi yang berkarakter yang sesuai dengan nilai dan norma Bangsa yaitu Pancasila. Dari analisis data diketahui juga bahwa lingkungan sosial budaya berpengaruh secara langsung terhadap sikap berkonsumsi mahasiswa begitupun dengan perilaku konsumsi yang berkarakter. Semakin baik lingkungan tempat tinggal mahasiswa baik tempat tinggal asal atau tempat tinggal sementara seperti kos maka pembentukan nilai-nilai terhadap perilaku konsumsinya juga semakin berkarakter. Perilaku konsumsi seseorang tidak lepas dari pengaruh lingkungannya. Berdasarkan penelitian Romu (2009) menemukan pengaruh sosial dan budaya di balik perilaku konsumsi yang beretika di Finlandia. Dari hasil analisis data juga diketahui pengaruh tidak langsung antara pembelajaran ekonomi terhadap perilaku konsumsi yang berkarakter melalui sikap berkonsumsi dan lingkungan sosial budaya terhadap perilaku konsumsi yang berkarakter melalui sikap berkonsumsi.

\section{KESIMPULAN}

Pembelajaran ekonomi memegang peranan penting terhadap sikap berkonsumsi yang membentuk perilaku konsumsi yang berkarakter pada mahasiswa. makin baik pembelajaran ekonomi yang diperoleh oleh mahasiswa maka makin baik pula sikap berkonsumsi mahasiswa yang sesuai dengan nilai-nilai budaya Bangsa yaitu Pancasila dan makin berkarakter pula perilaku konsumsi mahasiswa yang sesuai dengan nilai-nilai budaya Bangsa yaitu Pancasila. Lingkungan sosial budaya juga memegang peranan penting terhadap sikap berkonsumsi dan pembentukan karakter pada perilaku konsumsi yang berkarakter pada mahasiswa. Makin baik lingkungan sosial budaya mahasiswa maka makin baik pula sikap berkonsumsi mahasiswa yang sesuai dengan nilai-nilai budaya Bangsa yaitu Pancasila dan makin baik lingkungan sosial budaya mahasiswa maka makin berkarakter pula perilaku konsumsi mahasiswa yang sesuai dengan nilainilai budaya Bangsa yaitu Pancasila.

Studi ini memberikan kontribusi saran diantaranya: Bagi mahasiswa disarankan untuk lebih aktif dalam kegiatan pembelajaran dan kegiatan lingkungan sosial budaya 
agar perilaku konsumsi yang mereka lakukan bisa meningkatkan karakter sesuai dengan nilai-nilai luhur Budaya Bangsa. Bagi dunia pendidikan khususnya pendidik ekonomi diharapkan mampu meningkatkan kegiatan proses pembelajaran yang mengarahkan dan membentuk peserta didik menjadi manusia yang berkarakter dalam setiap perilakunya terutama peilaku berkonsumsi yang menjunjung tinggi nilai-nilai yang terkandung dalam pancasila. Bagi bidang keilmuan ekonomi diharapkan lebih banyak meningkatkan materi yang memasukkan nilai-nilai budaya Bangsa Indonesia yaitu Pancasila sehingga para subyek dan obyek pendidikan lebih menekankan perilaku mereka yang sesuai dengan jati diri Negaranya bukan nilai-nilai kapitalis yang tidak sesuai dengan jati diri bangsa.

\section{DAFTAR PUSTAKA}

Agil, Syed dan Syed Omar. 2007. Psychological behavior and economics: the need for new theories and rede_nition of basic concepts in Islamic economics. Unitar ejournal vol. 3 , no. 1 .

Aunurrahman. 2009. Belajar dan Pembelajaran. Bandung: Alfabeta.

Bany and Johnson. 1975. Educational Social Psychology. New York: Macmillan.

Deliarnov,1997. Perkembangan Pemikiran Ekonomi Edisi Revisi. Jakarta Raja Grapindo Persada.

Disman. 2004. Efektivitas Pendidikan Ekonomi dalam Pembentukan nilai-nilai Perilaku Ekonomi Kekeluargaan siswa SMA Negeri di Kota Bandung. (Online) http://repository.upi.edu/ diakses pada tanggal 10 Maret 2012.

Engel, James F. Blackwell Roger D. Miniard Paul W. 1994. Perilaku Konsumen jilid I (Terjemahan). Jakarta: Penerbit Binarupa Aksara

Hamalik, O. 2010. Kurikulum dan Pembelajaran. Jakarta: Bumi Aksara.

Irianto, Petrus. 2011. Pola Interaksi Konflik dan Reaktualisasi Pendidikan Karakter: Studi Survey Eksplanatori di Universitas Cenderawasih Jayapura Papua. (Online) http://repository.upi.edu/ diakses pada tanggal 16 Februari 2012. 
Koentjaraningrat, 1991. Kebudayaan Mentalitas dan Pembangunan. Jakarta: Gramedia Pustaka Utama.

Mubyarto dan Boediono (penyunting). 1981, Ekonomi Pancasila, BPFE:, Yogyakarta. Mu'in. 2011. Pendidikan Karakter; Kontruksi Teoritik dan Praktik; Urgensi Pendidikan Progresif dan Revitalisasi Peran Guru dan Orang Tua. Yogyakarta: Ar-Ruzz Media

Romu, Heidi. 2009. Ethical consumption as an identity project - A narrative approach to Finnish ethical consumers' identity construction. Marketing Master's Thesis. Helsinki School of Economics.

Sajogyo, 1982. Bunga Rampai Perekonomian Desa. Bogor: Yayasan Obor Indonesia dan Institut Pertanian Bogor

Schiffman \& Kanuk. 2004. Perilaku Konsumen (edisi 7). Jakarta: Prentice Hall

Soedarsosno, soemarno. 2005. Hasrat untuk Berubah; The Willingness to Change. Jakarta: PT. Gramedia. 